\title{
Beware of the dog! Septic shock due to Capnocytophaga canimorsus revealed on peripheral blood smear
}

\author{
Attention au chien! Choc septique à Capnocytophaga canimorsus \\ détecté sur le frottis sanguin
}

Florent Gosset ${ }^{1}$

Benoît Sarret ${ }^{1}$

Sébastien Mortreux ${ }^{2}$

Olivier Moquet ${ }^{1}$

${ }^{1}$ Centre de biologie du Nivernais, Centre hospitalier de l'agglomération de Nevers, Nevers, France

2 Service de réanimation polyvalente, Centre hospitalier de l'agglomération de Nevers, Nevers, France

\begin{abstract}
A blood smear examination led to the diagnosis of severe bacterial infection in a splenectomized patient. The knowledge of a relevant clinical information (recent dog bite) could have led to immediate presumptive identification of the causative agent, Capnocytophaga canimorsus.
\end{abstract}

Key words: Capnocytophaga canimorsus, thin blood smear, dog bite, asplenia, septic shock

Résumé. L'examen d'un frottis sanguin a permis de détecter rapidement au laboratoire une infection bactérienne sévère chez un patient splénectomisé. La connaissance d'un renseignement clinique adéquat (morsure de chien récente) aurait pu permettre de poser une identification présomptive immédiate de la bactérie impliquée, Capnocytophaga canimorsus.

Mots clés : Capnocytophaga canimorsus, frottis sanguin, morsure de chien, asplénie, choc septique
A 60-year-old man presented to the emergency department with fever and diarrhea since 6 hours.

He had a medical history of splenectomy for a splenic abscess.

Clinical examination showed a temperature of $40.7^{\circ} \mathrm{C}$, tachycardia, polypnea and slight wounds on the left hand.

The patient's condition rapidly worsened with confusion, metabolic acidosis, hypotension partially resistant to catecholamines and volemic filling.

He was intubated and transferred to the intensive care unit. Initial laboratory investigations were notable for elevated CRP (240 mg/L) and PCT (41 $\mu \mathrm{g} / \mathrm{L})$, neutropenia (1.2 G/L) and acute renal failure (creatinine $212 \mu \mathrm{mol} / \mathrm{L}$ ).

A May-Grünwald Giemsa-stained blood smear examination revealed Howell-Jolly bodies in erythrocytes, consistent with asplenia, Döhle bodies in neutrophils, and numerous extracellular and intracellular thin bacilli (figure 1).
Cefotaxim was started for 3 days.

One of 3 aerobic blood cultures turned positive in 17 hours. Subculture on chocolate agar incubated in $5 \% \mathrm{CO}_{2}$ grew in 48 hours and led to the identification by MALDI TOF of Capnocytophaga canimorsus

The patient's wife then reported that he had been bitten by a dog one week before.

Antibiotherapy was switched to amoxicillin-clavulanate for 7 days and the patient was discharged after 11 days and a full recovery.

Capnocytophaga canimorsus is an encapsulated, capnophilic, thin, Gram-negative bacillus found in the normal oral flora of dogs and cats [1].

It has emerged as a leading cause of severe infection after dog or cat bites and scratches [2].

Severe infections occur mainly in immunocompromised patients (alcoholism, malignancies), especially those with asplenia which is a well-known risk factor for infection by encapsulated pathogens.

The definitive diagnosis is based on culture, but may be delayed or missed due to fastidious culture and slow growth of the bacteria. 


\section{Biological pictures}

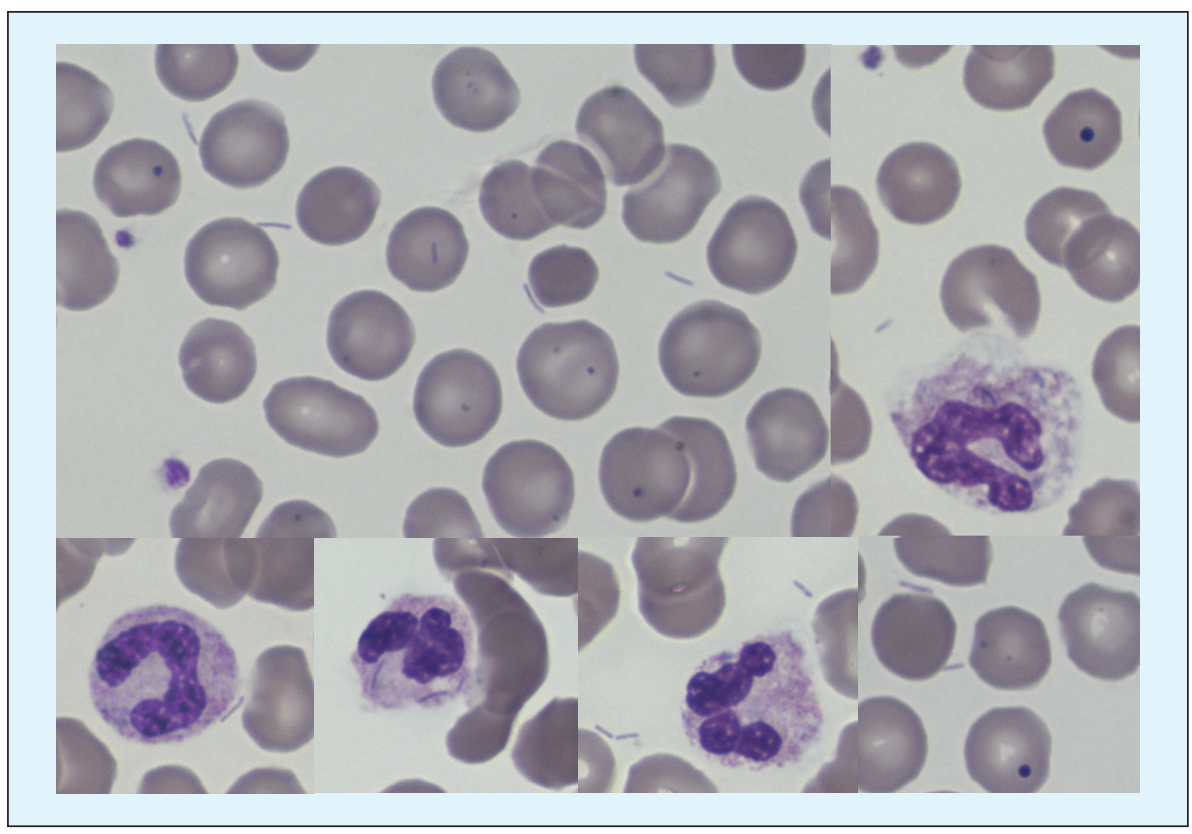

Figure 1. Thin blood smear revealing Howell-Jolly bodies in erythrocytes, extracellular and intracellular bacilli (May-Grünwald Giemsa stain, $\times 1,000$ magnification.

The blood smear examination can lead to a rapid presumptive diagnosis if a relevant clinical context is communicated to the laboratory.

Conflict of interest : none of the authors has any conflict of interest to disclose.

\section{Références}

1. Brenner DJ, Hollis DG, Fanning GR, Weaver RE. Capnocytophaga canimorsus sp. nov, (formerly CDC group DF-2), a cause of septicemia following dog bite, and C. cynodegmi sp. nov., a cause of localized wound infection following dog bite. J Clin Microbiol 1989; 27 :231-5.

2. Butler T. Capnocytophaga canimorsus: an emerging cause of sepsis, meningitis, and post-splenectomy infection after dog bites. Eur J Clin Microbiol Infect Dis 2015; 34(7) : 1271-80. 